\title{
Nonrepresentational Theory and Symbolic Interactionism: Shared Perspectives and Missed Articulations
}

\author{
Phillip Vannini \\ Royal Roads University
}

\author{
Non-Representational Theory: Space, Politics, Affect \\ By Nigel Thrift \\ London: Routledge, 2008 \\ $\$ 160.00$ (cloth); \$51.95 (paper)
}

Nigel Thrift's Non-Representational Theory is the latest-and more coherently and thoroughly formed - of his recent attempts to develop the ontological foundations and the practical agenda of an interdisciplinary theoretical perspective that has come to be known as nonrepresentational theory. Nonrepresentational theory is still largely unknown in North America, though its growth in European (primarily British) academic circles over the last five years has been impressive. Originating within human geography but expanding rapidly across the social sciences, nonrepresentational theory is a mosaic of ideas borrowed from fields as different as performance studies, material culture studies, contemporary social and cultural theory, political economics, ecological anthropology, biological philosophy, cultural studies, the sociology of the body and emotions, and the sociology and anthropology of the senses. Theoretically, nonrepresentational theory stands as a synthesizing effort to amalgamate diverse but interrelated theoretical perspectives such as actor-network theory, biological philosophy, neomaterialism, social ecology, performance theory, post-structuralist feminism, critical theory, and interactionism and pragmatism. In light of Thrift's close attention to both the intellectual historical heritage of classical pragmatism - in particular to the thought of Peirce, James, and Dewey - and to more recent manifestations of symbolic interactionist theory and research, it seems apropos to reflect here on the relation between interactionism and nonrepresentational theory and thus to tease out points of convergence and missed articulations.

An extended review and reflection on Thrift's book is also important because Non-Representational Theory is hardly a primer, and therefore a "translation" of sorts might win additional converts. Thrift's writing is indeed extremely dense, and, while clear, his use of terminology is bound to alienate even the most daring of the

Symbolic Interaction, Vol. 32, Issue 3, pp. 282-286, ISSN 0195-6086, electronic ISSN 1533-8665. (C) 2009 by the Society for the Study of Symbolic Interaction. All rights reserved. Please direct all requests for permission to photocopy or reproduce article content through the University of California Press's Rights and Permissions website, at http://www.ucpressjournals.com/reprintinfo.asp. DOI: 10.1525/si.2009.32.3.282. 
noninitiated readers. The book's pages, for example, are literally filled with dozens and dozens of long quotes that, on more than a few occasions, take away from the continuity of his arguments and abduct the reader on a wild journey across an impressively, but dauntingly, vast field of ideas. Thrift's erudition and in particular his familiarity with extremely recent philosophical literature is outstanding, but at times his attention to multiple theoretical strands makes his writing lose touch with the concrete, leading the reader to wonder whether nonrepresentational theory is destined to take exclusive form as abstraction, or whether the possibility for systematic research application exists. Thrift's attention to topics that many readers — of this journal at least-might find preciously indulgent and esoteric (e.g., affective spaces of political performance, the politics of urban trauma, networks of cyborgian affective intelligence, the growth of qualculation, capitalism's epistemic ecology, etc.) could also get in the way of the reception of what is, without the shadow of a doubt, a foundational book destined to become a turning point in the progressive abandonment of (post)structuralism, foundationalism, and realism, as well as in the coagulation of previously separate interdisciplinary theoretical and empirical traditions. But before reflecting on the potential usefulness of nonrepresentational theory for interactionist theory and research, let me briefly summarize its main tenets as outlined by Thrift.

\section{Nonrepresentational Theory's Principles}

In a difficult, but remarkably clear, well-organized, and contagiously enthusiastic first chapter, Thrift outlines seven core principles, or ideal qualities, of nonrepresentational theory. In the preface Thrift is quick to point out that his intent in territorializing nonrepresentational theory is to outline a new experimental genre: a hybrid genre for a hybrid world. The seven principles, therefore, are to be understood as a tentative formation of a new landscape that is liable to enliven - through the "application of a series of procedures and techniques of expression" (p. 2) - a new hybrid: a science/art that works as an interpretive "supplement to the ordinary, a sacrament for the everyday, a hymn to the superfluous" (p. 2). Therefore, the seven principles are to be taken neither as laws nor as root images, but instead as exercises in creative production and as "practices of vocation" (p.3) meant for an imprecise science more concerned with hope for politico-epistemic renewal than validity.

With this said, nonrepresentational theory's first programmatic tenet is to "capture the 'onflow' ... of everyday life" (p. 5). Life is movement-geographic and existential. Life is a becoming in time-space moved by the "desire to do more than simply squeeze meaning from the world" (p.5). Existence is marked by an intentionality-a Deweyan qualitative immediacy of sorts-that transcends consciousness, and by an effervescent energy that shows that "thought is never an object in its own hands" (James 1960:522, cited in Thrift 2008:6). Nonrepresentational theory therefore rejects the cognitive tendencies of radical empiricism, emphasizing the power of the precognitive as a performative technology for adaptive living, as an instrument of sensation, play, and imagination. 
Second, "non-representational theory is resolutely anti-biographical and preindividual." Autobiography "provide[s] a spurious sense of oneness," whereas biography offers a "suspect intimacy with the dead" (p. 7). What Thrift-borrowing here from Freud-seems to fear is biography's ambition to find, as well as construct, an artificial sense of individual wholeness and hermeneutic coherence. Of all seven principles this is arguably the most obscure, as Thrift fails to specify what precise types of biographical work he is most inimical toward, what further reasons he hasbesides the sloganlike remarks reported above-for conflating biography with humanistic whole-ism, and whether his criticism extends to more contemporary forms of narrative inquiry. Together, tenets one and two constitute nonrepresentational theory's criticism of methodological individualism, a point further elaborated on later in this review essay.

Third, nonrepresentational theory concerns itself with practice, action, and performance. Thrift is weary of the structuralist heritage of the social sciences and suspicious of all attempts to uncover symbolic meaning where other, more practical forms of meaning exist. Relying primarily on performative approaches to joint actionsuch as the Peirce-inspired anthropological theory of art and technology of Alfred Gell-and on Deleuzian philosophy, Thrift puts a premium on the corporeal routines and rituals that establish meanings in embodied action-a point clearly shared with interactionism and pragmatism.

Fourth, nonrepresentational theory is built on the principle-borrowed primarily from actor-network theory-of relational materialism. Material objects are no mere props for performance but parts and parcel of hybrid assemblages endowed with diffused personhood and relational agency. "The human body"-Thrift tells us_-"is what it is because of its unparalleled ability to co-evolve with things" (p. 10). In this sense material objects are to be given the same conceptual and empirical weight that is warranted to their human companions. Things form a "technological anteconscious" (p.10) with the human body's nervous system, and therefore nonrepresentational theory ought to reject any separation between corporeality, materiality, and sociality.

Fifth, nonrepresentational theory is meant to be experimental. Thrift has a deep antipathy for the hyperempirical excesses of the traditional social sciences, for the conventions of realism, and-obviously-for any manifestation of positivism. By invoking the expressive power of the performance arts Thrift calls on social scientistscum-artists to "crawl out to the edge of the cliff of the conceptual" (Vendler 1995:79, cited in Thrift 2008:12) and to engage in a battle against methodological fetishism: a "poetics of the release of energy that might be thought to resemble play" (p. 12). By refusing a social science obsessed with control, prediction, and the will to explain and understand everything, Thrift calls for a sense of wonder to be injected back into the social sciences. Alas, incidentally, this sense of wonder remains both unspecified and absent from Thrift's writing, or at least it gets buried under the burdensome weight of his constant theorizing.

Sixth, Thrift stresses the importance of affect and sensation. He views the senses and emotions not as subjects for micro-sociological empirical attention but as the engine of political regeneration driving the new politics and ethics of hope that he 
proposes. Here is where Thrift admits to retaining a certain measure of humanism and an obvious affection for Simmel, James, and especially Dewey, whom he praises as a champion of embodied, antidualist, aesthetically sensitive "sensuous scholarship" (p. 148). Peirce's influence on Derrida and Deleuze, and James's theory on the sociality of emotions, are also key in retaining a sense of "personal authorship" of one's life while rejecting fixity, the conflation of personhood with subjectivity, and the centrality of rationality and reflexive consciousness.

At last, the seventh tenet of nonrepresentational theory stresses an ethic of novelty suggesting "a particular form of boosting aliveness" (p. 14) and a promissory, regenerating Jamesian potentiality: the "jump to another world" (p. 15). Traditional ethical systems will not suffice for Thrift, built as they are on traditional humanistic principles of a univocal human subject, "transparent, rational, and continuous" (p.14). A new ethics built on the craftsmanship of everyday life and existing on the "interstices of interaction" (p.15) is liable to "build new forms of life in which 'strangeness itself [is] the locus of new forms of neighborliness and community' (Santner 2001:6)" (p. 14). Nonrepresentational theory's seven tenets are meant to sensitize social scientists to the fact that "they are there to hear the world and make sure that it can speak back, just as much as they are there to produce wild ideas," "to render the world problematic by elaborating questions," and to open research and theorizing to "more action, more imagination, more light, more fun, even" (pp. 18-20).

\section{Articulating Nonrepresentational Theory and Symbolic Interactionism}

Despite Thrift's coherent attempts to add pieces of pragmatism and interactionism to the nonrepresentational theory puzzle, it is easy to remain unconvinced that the two theoretical perspectives are closely related, at least in practice. Even though it is arguably true that at least six of the core tenets of nonrepresentational theory are perfectly congruent with the more processual versions of symbolic interactionism (the jury is still out on the second tenet indicated above), Thrift's tendency to equate nonrepresentational theory with a seemingly postconceptual, postempirical social science ought to raise some skepticism among interactionists.

In particular, Thrift's veiled criticisms of ethnography and interviewing - both accused of being overly "cognitive in origin and effect" (pp. 147-48)-lead this reader to wonder what options, according to Thrift, are available for a researcher keen on collecting empirical material while avoiding the pitfalls of representationalism. Thrift does indicate that the goal of a nonrepresentational enterprise is to avow for the generation of multiple "performative methodologies which allow their participants equal rights to disclosure, through dialogical actions rather than texts, through relation rather than representation" (p. 148), but aside from summarily listing as likely candidates for this performative turn the usual suspects (art, sculpture, theater, dance, poetry, music), Thrift neither sufficiently demonstrates what these artistic genres ought to be like when combined with the social sciences nor explains how these modes of expression ought to draw multiple bodies of knowledge from the 
sociomaterial world. In other words, while it is certainly captivating to hope that the marriage between the performative arts and the performative social sciences ought to give birth to new possibilities, to new relations, and to new ways of constructing everyday life, it remains entirely to be seen what will happen when "theory ends [and] something else takes its place" (p. 148). Perhaps methodological options like arts-based inquiry, performance ethnography, and narrative/reflexive ethnography do in fact feature the playful, performative, sensual, expressive, and heteroglossic properties of the nonrepresentational paradigm, but Thrift neglects to examine their potential — or even display signs of familiarity with them — as he dismisses ethnography and biography writ large as overly preoccupied with methodological rigor.

If any further articulation between symbolic interactionism and nonrepresentational theory can indeed take place-and it is my opinion that both perspectives would benefit from this-some work must be done on both sides of the bridge. On the symbolic interactionist end, all forms of realism-for realism is after all the will to power underlying all forms of representationalism-must be rejected. A nonrepresentational interactionism ought to take distance from cognitivism and discursivity, ought to emphasize the playfulness of both human action at large and of research itself as token of that action, and ought to free itself from the shackles of the life-flattening coding-and-excerpting imperative that so deeply marks much of qualitative research reporting. Moreover, nonrepresentational interactionism could and should retain its constructivist ontology while surrendering its skepticism toward neomaterialism and the poetics of nonlinguistic reflexivity. Thus a nonrepresentational interactionism could learn to add to the world, to abduct from it, rather than just to subtract from it; it could fully embrace the principles of "messiness," of "wonder," and combine its traditional "pragmatics of error" (p. 170) with a newer reflexive mode of interpretation that is vital, imaginative, and understated.

On the other end of business, nonrepresentational theory must come to grips with its "theory-ness." Despite Thrift's pronouncements, no new styles of thought are present in his book. Nonrepresentational theory could very well be a new "approach to understanding the world in terms of effectivity rather than representation" (p.113) based on "activating powers of invention" and the "potential of stylistic free variation" (pp. 112-13), but it cannot be what it aspires to without a concrete, passionate, even erotic attachment to the rhythms, the places, the humanist contours, the doldrums, and the delightfully excruciating minutiae of personal lives. In other words, nonrepresentational theory is condemned to retain the flavors of the grandtheorizing it abhors if it does not develop a new, but oh-so-old attitude toward getting the seat of one's pants dirty in the "ongoing rearrangement of objects and symbols within a field involving the body" (p. 116) — a field that is phenomenologically experienced, situated, carnally lived, narrated, and reflected on by a nonrepresentational unapologetic researcher, and not just a theorist. In sum, if symbolic interactionism can gain by becoming less representational through an articulation with nonrepresentational theory, what nonrepresentational theory can gain from a marriage with interactionism (and good ethnography too) is to be a bit less anti-representational. 